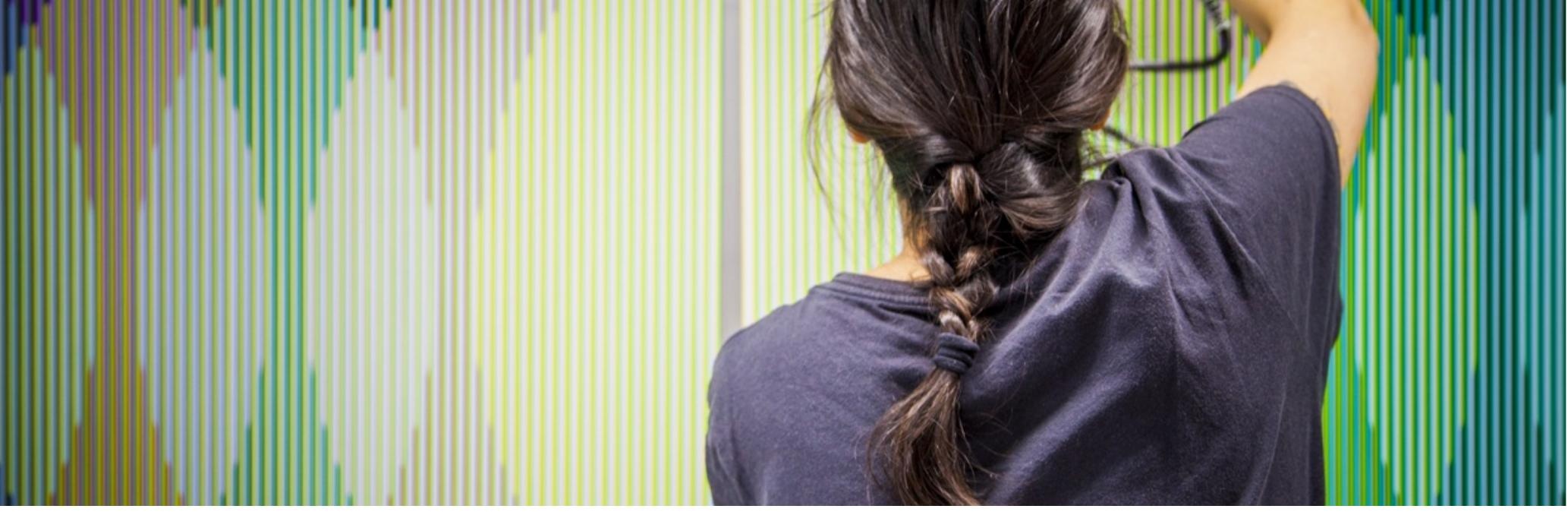

\title{
Cruz-Diez: El surgimiento de una familia - Rise of a family.
}

Authors: $\quad$ Felicitas Holzer, María Fernanda Sandoval

Submitted:

23. December 2018

Published:

28. December 2018

Volume:

Issue:

5

10

Affiliation:

Languages:

Keywords:

Categories:

University of Buenos Aires

Spanish, Castilian

Interview, Adriana Cruz, Carlos Cruz Diez, Foundation, Paris, Venezuela

Abstract:

News and Views, Visual Arts, Architecture and Design

DOI: $\quad$ 10.17160/josha.5.10.516

The JOSHA Team had two times in this year the great opportunity to visit not only the atelier but also the Carlos Cruz-Diez Foundation in Paris, France. Our second visit was an incredible interview with the daughter of this grate Op-Art and president of the Foundation, Adriana Cruz Diez. She said: "My father is clearly the creator and the person with the ideas. We, the other family members, are helping. We are aware that we are in a privileged position to do so". Carlos Cruz-Diez, born in Caracas in 1923, belongs to the avant-garde of so-called op art and kinetic art and is already titled "Master of Color." 


\section{Cruz-Diez: El surgimiento de una familia}

\section{Entrevistai con Adriana Cruz- \\ Diez, hija del artista Op-Art \\ Carlos Cruz Diez y presidenta \\ de la Fundación de Arte Cruz-}

Diez

Por Felicitas Holzerii y María Sandoval ${ }^{\mathrm{iii}}$

Conocemos a Adriana Cruz Diez en París, futura heredera y administradora de un impresionante legado artístico, más precisamente el de su padre Carlos. Carlos Cruz-Diez, nacido en Caracas en 1923, pertenece a la vanguardia del llamado OpArt y del arte cinético y desde hace mucho tiempo se ha titulado "Master of Colour". Junto con Victor Vasarely y Jesús Rafael Soto, compatriota de Cruz-Diez, es uno de los protagonistas del movimiento Op-Art en París, donde se instaló ya en 1960. Actualmente dirige un estudio en el distrito 18 de París, donde numerosos miembros de su extensa familia participan en las obras de arte según la tradición latinoamericana. Cruz-Diez, que cumplió 95 años en agosto y aún tiene la cabeza llena de ideas y planes sobre cómo desarrollar su arte por lo que su

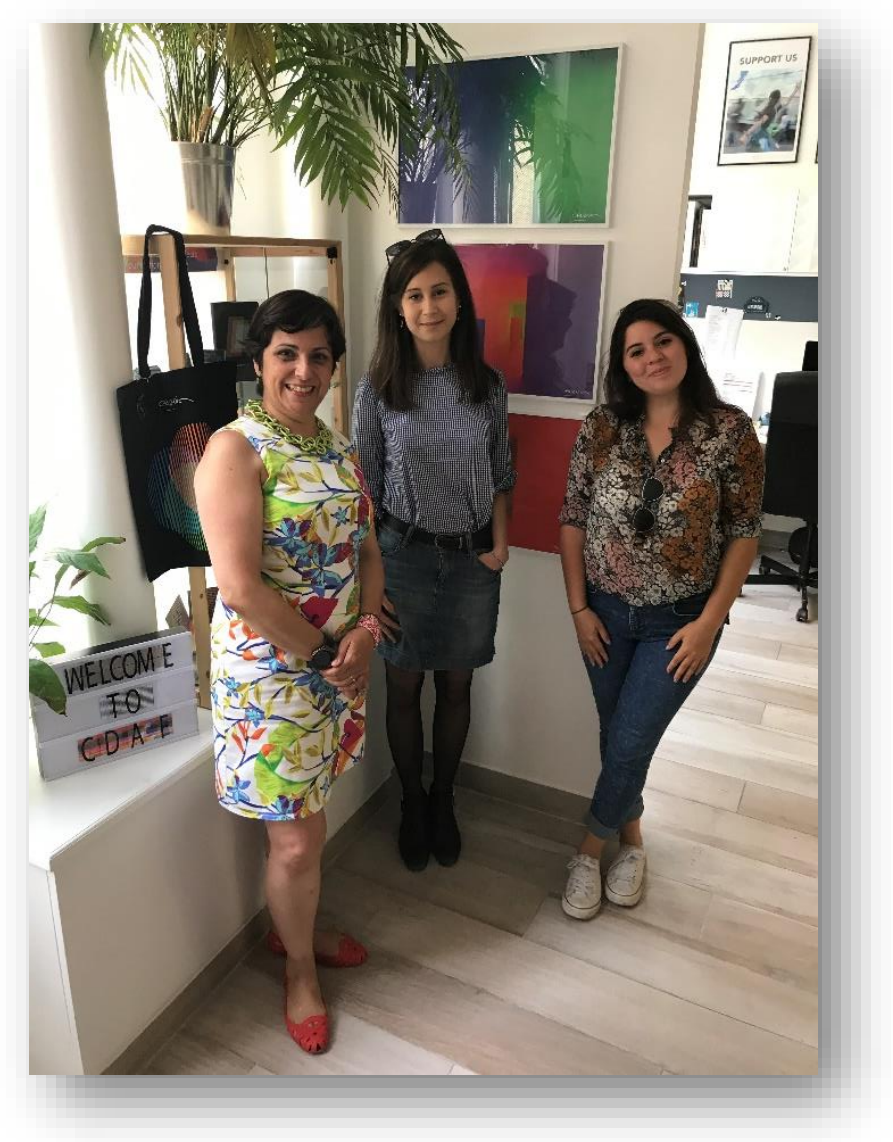

familia no cree que se le esté apagando el espíritu. Hoy en día, la hija menor de Cruz Diez, Adriana, es presidenta de la Fundación Cruz-Diez y dirige un notable legado de arte, exposiciones en todo el mundo y colaboraciones con galerías. En el centro de su trabajo se encuentra la visión como fuente de inspiración para despertar la curiosidad, la alegría del descubrimiento y el pensamiento no convencional en la gente.

Adriana habla de su infancia, de su familia y del arte de su padre. Pronto se hace evidente que el arte de Cruz-Diez, aunque la forma, el lenguaje del color y la visión sean concebidos por el propio Maestro, se basa en un trabajo familiar en conjunto. La Fundación de Arte Cruz Diez está ubicada en una calle tranquila entre los distritos 9 y 
10. Al entrar en las acogedoras habitaciones, es imposible perderse los grabados artísticos de Cruz-Diez colgados en las paredes. Los relieves de lamas transparentes y de colores cambian de color a medida que se camina. Los cuadros cuyas franjas de color consisten sólo en blanco, negro y azul destilan una delicada aura amarilla. Los cuadros, sin embargo, sólo muestran una pequeña parte de la extensa obra del artista.

\section{FH: Adriana, ¿dónde y cómo creciste o cómo viviste tu infancia?}

ACD: Mi padre siempre ha vivido en y con el arte. Estrictamente hablando, nunca trabajó, pero siguió su pasión, el arte. Al principio mi padre trabajaba mucho en casa, porque aún no tenía su propio estudio, así que parte de la casa fue convertida en un estudio.

\section{FH: ¿Y ese estudio estaba en París en ese entonces?}

ACD: Sí, exactamente. Mi padre llegó a Europa muy temprano. En 1955 estuvo en España, en Barcelona, y después de algunas idas y venidas se dijo a sí mismo en 1960 que quería quedarse en París. Mis dos hermanos mayores, mi madre y yo, siempre lo acompañábamos. Estaba claro que para mi padre el arte sería el leitmotiv de su vida, apoyado y hecho posible por un fuerte vínculo familiar. Cada vez que mi padre iba a vernissages o a una nueva exposición, toda la familia viajaba con él. Para nosotros, los niños, viajar a Florencia, Madrid, etc. a veces nos parecía una fiesta. Las conversaciones en el círculo familiar eran muy a menudo sobre los proyectos y exposiciones de mi padre, así como sobre su teoría de los colores. Después de la escuela y especialmente durante las vacaciones se nos permitió ayudarlo con su trabajo desde el principio, un trabajo que requería mucho tiempo, paciencia y un trabajo meticuloso con los dedos.

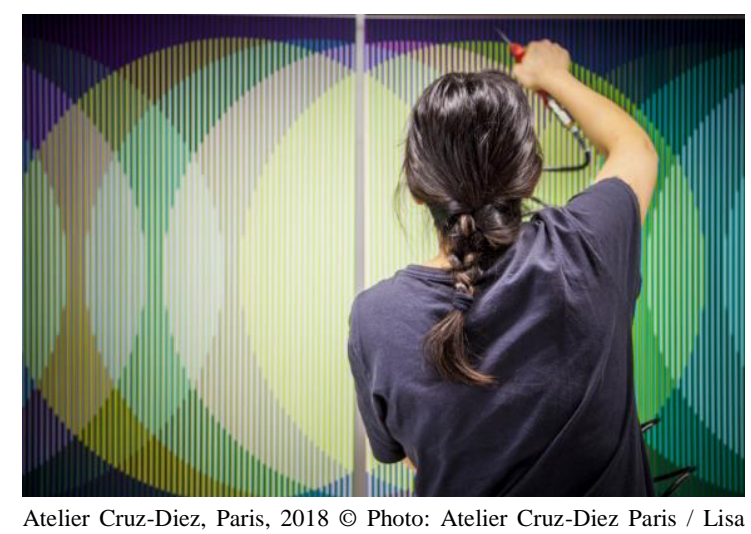
Preud'homme

MS: ¿Se ha preguntado en algún momento en qué dirección iría la "compañía de arte" Cruz-Diez? ¿Estuvo siempre claro que el nombre Cruz-Diez existiría como un negocio familiar?

ACD: La vida cotidiana de un Cruz-Diez suena muy atractiva a primera vista. Pero mis dos hermanos mayores y yo teníamos nuestros propios proyectos junto con el trabajo de mi padre. Por ejemplo, soy diseñador gráfico y durante un tiempo tuve mi propia pequeña empresa dentro del estudio Cruz-Diez. Más tarde decidí trabajar fuera del estudio para empresas internacionales, simplemente para tener esta experiencia. Sin embargo, cuando mi madre murió en 2004, mi hermano Carlitos y yo decidimos volver al negocio familiar. Mi padre tenía una carrera muy dura en ese 
momento y necesitaba apoyo porque la muerte de mi madre le afectó mucho. Desde 2005 hemos profesionalizado el estudio, es decir, contratado asistentes y puesto al día el trabajo de relaciones públicas. Con todo, hoy me siento mucho mejor preparado para dirigir la Fundación Cruz-Diez. Creo que todos los miembros de la familia tienen la libertad de adquirir experiencia fuera de los lazos familiares, pero nadie se queda dormido por completo. Todos nos mantendremos al tanto de lo que sucede en casa.

MS: ¿Se mantendrán los lazos laborales y familiares de los nietos de Carlos CruzDiez?

ACD: Sí, en realidad. Mis dos hijas, Alicia e Irene, por ejemplo, estudiaron en el extranjero. Alicia vive en Londres, donde ya lleva un año trabajando de forma independiente en un proyecto relacionado con el diseño de interiores. Sin embargo, vio que los otros nietos trabajaban con su abuelo durante las vacaciones y decidió volver al negocio familiar.

FH: Tus historias hacen que parezca muy natural que todos los miembros de la familia participen en el arte del Maestro. Pero ¿no es realmente extraordinario que todos ustedes muestren tanta motivación y entusiasmo para participar en el trabajo de su padre?

ACD: No es como si estuviéramos en el estudio todos los días. Pero lo cierto es que todos crecimos con el trabajo de Cruz-Diez en nuestro entorno familiar cercano. Ahora ya hay una bisnieta; todavía es pequeña, pero quién sabe, tal vez se una a nosotros en el futuro. Creo que todos nosotros, tan diferentes como somos, o quizás precisamente por eso, podemos contribuir a la empresa familiar. Nuestras diferentes perspectivas, visiones, talentos $\mathrm{y}$ experiencias conducen a hacer que la empresa familiar tenga sentido. Mi hija Alicia, por ejemplo, nos informa sobre las exposiciones en Londres y así contribuye a la compañía, aunque ella no vive en París en absoluto. Cuando establecimos la fundación en 2005, pensamos que necesitábamos construir algo formal. Sin embargo, rápidamente nos dimos cuenta de que esto también funciona muy bien "informalmente" dentro de nuestros lazos familiares.

MS: ¿Cómo se ha desarrollado la empresa familiar y su arte? ¿Qué influencia tiene hoy en día el mundo digital y las redes sociales?

Esa es una pregunta interesante. Mi padre siempre estuvo muy interesado en experimentar en el campo del color, que sigue siendo un campo de arte muy virgen hoy en día. Trabaja hoy en día con el ordenador, lo que, por supuesto, no siempre ha sido el caso. Pero mi padre siempre ha integrado con entusiasmo en sus obras todas las nuevas técnicas que están surgiendo, la posibilidad de la impresión digital, el uso de plásticos, etc. Utiliza nuevas técnicas como herramientas para desarrollar su arte. Su trabajo es una constante actividad de investigación. Quizás por eso sigue siendo tan atractiva, especialmente para los jóvenes. Cuando las primeras impresoras de inyección de tinta 
salieron al mercado, no podía dejar de jugar con ellas hasta que la máquina estuviera lista para su arte.

MS: Cuando vemos los videos de tu padre en Instagram, por ejemplo, vemos la gran energía y alegría que transmite. ¡Eso es impresionante a los 95 años!

ACD: En efecto. Eso es lo que todos dicen. Bueno, mi padre siempre tiene un proyecto en marcha, y creo que eso es lo que lo mantiene vivo. Otra cosa que siempre he admirado de él es su curiosidad por explorar la curiosidad y entender cómo funcionan las cosas. Lee mucho, pero también habla con cualquier persona, para conocer y entender cosas nuevas. Creo que nunca podría haber dominado inmensas obras arquitectónicas sin esa curiosidad. Queremos transmitir esta energía y actitud positiva como fundamento.

FH: ¿Podría describir brevemente de qué se trata el arte de Carlos Cruz-Diez? ¿Cuál es el significado del color, cuál es el significado del espectador?

Mi padre ya desde muy temprano se interesó en cómo podría acercar el arte, incluso a los no especialistas. Siempre se ha quejado de la desigualdad social y la pobreza en Venezuela y ha querido cambiar y desarrollar el arte para que sea accesible a las personas que tienen menos recursos. En su opinión, el arte debería salir de los museos en donde se encuentra herméticamente sellado y precisamente fuera del alcance de muchos.
Bueno, por su trabajo. ¿Qué lo hace un artista? Mi padre ve en un artista a una persona con una visión de conjunto. En la época de Rubens, en el siglo XVII, por ejemplo, había muchos especialistas que trabajaban con mucho cuidado cada detalle de la pintura, como los especialistas en manos, cabello, etc... Pero sólo uno de ellos tenía a la vista la totalidad del cuadro e instruyó a los demás para que integraran los detalles en una obra artística. Otra metáfora de mi padre: el director de la orquesta es el que reúne las voces individuales en un todo armónico. La obra de Carlos Cruz-Diez es conocida por sus experimentos de color y composiciones. Yo considero, además, que mi padre reúne los componentes individuales de color para formar una obra de arte. Él es el arquitecto.

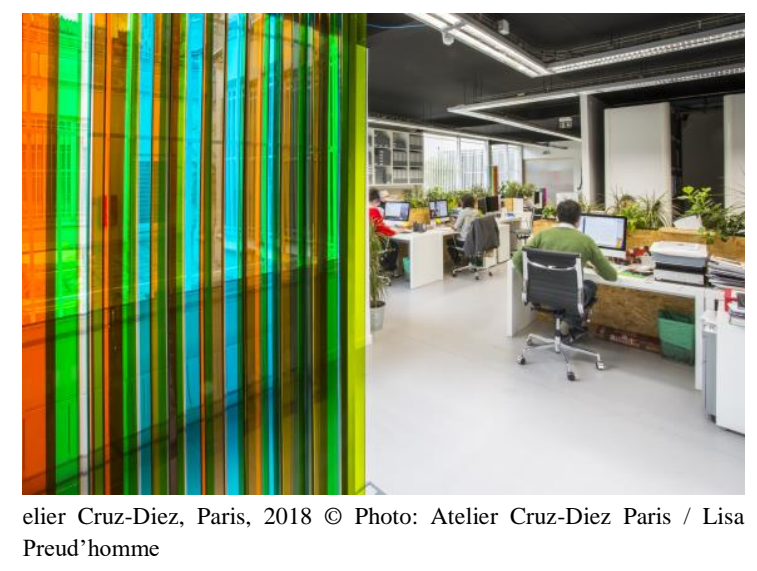

MS: ¿Qué papel desempeña el observador, cuán importante es, o puede incluso desempeñar el papel principal en la obra de arte?

ACD: El observador juega un papel decisivo en la obra de arte. Complementa, por así decirlo, la obra de arte, completa lo que el artista comenzó. Además, mi padre 
como artista tiene la intención de que nosotros como espectadores disfrutemos del juego de colores. Como consumidores de arte formados, a menudo entramos en exposiciones con opiniones preconcebidas que consisten en transferir al arte lo que ya se ha leído. Pero la visión de mi padre es que el espectador viva en el momento y en el arte cuando lo mire. Los niños son particularmente receptivos a los juegos de color, pero no porque entiendan la teoría que hay detrás de ellos, sino porque disfrutan del color en este momento. En Metz, una de las exposiciones actuales, había niños que corrían por el suelo con una impresión en color y no podían dejar de mirar el juego de colores. Se supone que el arte de mi padre estimule y actúe exactamente de esta manera.

FH: El objetivo es, por así decirlo, sacar al observador de su papel pasivo como observador.

ACD: Exactamente.

MS: Ahora hay mucha literatura sobre el arte de tu padre; su arte se ha convertido en un tema académico, no sólo en cuanto a la estética, sino también en el ámbito sociopolítico. ¿Se puede hablar ya de una "era" o "época del arte" Cruz-Diez?

ACD: Pregunta difícil. Mi padre ya había comenzado sus primeros experimentos de color en 1950 y sigue experimentando felizmente en la actualidad. La obra de mi padre es formalmente la misma: $\mathrm{La}$ "Fisicromía" ya existía en los años sesenta; sin embargo, las obras de esa época son sobre todo históricamente interesantes. Por por otro lado, las fisicromias de hoy son más ricas, más sofisticadas y en ellas se pueden ver los años de trabajo de mi padre. Cada nueva forma de experimentar y hacer arte con nuevos materiales le abrió y sigue abriendo nuevas puertas.

FH: ¿Es el arte de Cruz-Diez universal? Es decir, ipodemos entenderlos desprendidos del contexto cultural y del horizonte temporal?

ACD: Definitivamente así lo creo. El arte no necesita pasaporte. Creo, sin embargo, que esto puede decirse de cualquier obra de arte. Una película excepcional de principios del siglo XX todavía puede serlo hoy en día. El arte reflexivo es una creación del hombre. Es universal.

FH: Lo pregunto porque los relativistas culturales lo verían de otra manera.

ACD: La cultura siempre influye en una obra y establece y limita las posibilidades de interpretación. Por ejemplo, en Francia, las obras de Shakespeare se traducen al francés y se representan. En Inglaterra uno ni siquiera se atrevería a traducir las piezas a un inglés más moderno, ya que esto sería una falta de respeto a la obra de arte. Bueno, estas son adaptaciones culturales. Tal vez es similar al arte de mi padre. Al final, sólo puede generar un tipo de experiencia. Lo que el observador haga con él depende de él.

FH: Pero en el fondo su arte es universal. Se nos da igualmente a todos nosotros y es comprensible a través de nuestra condición humana. 
ACD: Una de sus obras de arte es una instalación en la UBS suiza. Creo que esto demuestra el alcance universal de su arte: incluso los suizos pueden hacer algo con estos colores tropicales.

\section{MS: ¿Cuál es el futuro del Op-Art o arte cinético?}

ACD: El movimiento Op-Art fue ante todo una reunión de individuos con visiones similares. El movimiento ya nació en los años 50. Hoy en día, la gente juega con él, sobre todo gracias a las nuevas tecnologías, la digitalización y las simulaciones de color por ordenador. Esto ha producido nuevos artistas interesantes. Mi padre nunca vio el Op-Art como una disciplina académica, sino como un viaje de descubrimiento. Los impresionistas ya se han hecho la pregunta del color y la representación del color. Su idea era capturar el momento del color y la experiencia en una sola imagen. Es decir, si la catedral estaba iluminada de rosa, estaba pintada de rosa, si era azul, entonces azul. Mi padre se preguntó entonces cómo pueden tener lugar gradualmente todas estas experiencias de color. Sus obras permiten no sólo una instantánea, sino el desarrollo temporal del color. El proyecto de mi padre es, por así decirlo, desarrollar más la idea de los impresionistas que lo inspiraron.

MS: ¿Hay algún plan futuro para la familia Cruz-Diez en cuanto a cómo se puede o se va a desarrollar la obra del Maestro?
ACD: Mi padre es claramente el creador y la persona con las ideas. Nosotros, los otros miembros de la familia, estamos ayudando. Somos conscientes de que tenemos una posición privilegiada para hacerlo. Es cierto que con el paso del tiempo ambos estudios, en Panamá y también en París, se han abierto a otros artistas y se han iniciado nuevas colaboraciones. De este modo, los estudios pueden acompañar a los nuevos artistas en su camino y no sólo reproducir las creaciones del Maestro. Como fundación, por supuesto, estamos interesados principalmente en hacer que el arte sea accesible al público, lo que considero sobre todo una tarea educativa.

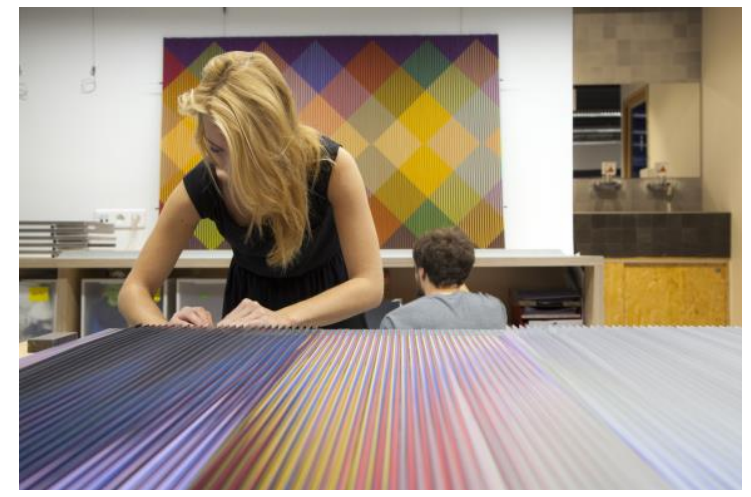

telier Cruz-Diez, Paris, 2018 (C) Photo: Atelier Cruz-Diez Paris / Lisa Preud'homme

MS: Finalmente: ¿Cómo es ser la hija de Carlos Cruz-Diez?

ACD: En primer lugar, maravilloso, porque amo y admiro mucho a mi padre. Es una persona muy cariñosa, que muestra mucho cariño hacia su familia, aunque siempre fue una persona muy trabajadora. Realmente aprecio su trabajo. Pero una cosa que he aprendido a apreciar especialmente de él es que hay que creer en sus proyectos. $\mathrm{Mi}$ padre ha dejado su casa con muchas 
obligaciones y obligaciones ya establecidas; estaba casado y tenía hijos. Aunque los primeros días fueron en París duro y marcado por la inseguridad social, pero aun así trabajó persistentemente y muy estructurado. Las ideas necesitan estructura. Y finalmente, su plan funcionó. La belleza de nuestra familia es que somos libres de hacer lo que queramos. Todos hablamos varios idiomas, vivimos en diferentes lugares y aun así seguimos siendo una familia. Y mi padre nos ha demostrado que se necesita valor. Si no conoces el lugar donde estás, si no hablas el idioma, entonces lo aprendes y te instalas. Lo que cuenta es creer en su proyecto.

FH: ¿Hubo alguna vez una época sombría en el imperio de los colores, una crisis en la vida del Maestro?

ACD: Una de sus grandes fortalezas es su optimismo y fe. Tuvimos momentos difíciles y también hermosos en la vida, como todos los demás. Sin embargo, aprecio en mi padre y en toda la familia una actitud básica que es muy positiva. También tengo que decir que siempre hemos estado rodeados de gente agradable. Fue entonces cuando mi padre recibió inesperadamente una buena suma de dinero por una exposición y así pudo comprar un apartamento.

\section{MS: ¿Cuáles son sus proyectos actuales?}

Afortunadamente, siempre tenemos mucho que hacer en el estudio. Actualmente estamos planeando un volumen arquitectónico con contribuciones de invitados que presentan una perspectiva sociológica sobre el arte callejero de mi padre. Para este volumen todavía recaudamos contribuciones y para fin de año el conjunto debería estar en pie. Luego tenemos una exposición que no es tan conocida, pues no todos conocen su faceta como fotógrafo. La exposición será de su trabajo fotográfico en blanco y negro.

\section{FH: ¿así que no hay colores?}

ACD: Así es. Mi padre era escéptico al principio, porque es conocido principalmente por sus experimentos de color. Pues bien, esta exposición ya ha sido exhibida en Venezuela, Nueva York, aquí en París en la Maison de l'Amérique Latine, y también en la Aliance Francaise en Panamá.

MS / FH: Muchas gracias, Adriana. MS: Pero una cosa que tienes que decirnos, ¿qué hace el Maestro para mantenerse tan en forma a los 95?

Siempre dice que está haciendo lo contrario de lo que los médicos le dicen que haga. El simplemente disfruta de todo en medidas $\mathrm{y}$ no en exceso.

\section{MS: Muchas gracias.}

Para más información, no duden en visitar la página de la fundación:

\section{Cruz-Diez Art Foundation}


' El siguiente extracto de la entrevista contiene una selección parcial de preguntas y respuestas. La entrevista completa dura 1:21 horas.

ii Felicitas Holzer es editora de la revista en línea "Josha Journal" y tiene un doctorado en filosofía política y bioética de la Universidad de la Sorbona en París, en colaboración con la Universidad de Buenos Aires. Ha estudiado economía, filosofía y ciencias biomédicas en Munich, Buenos Aires, Cambridge y París. iii María Sandoval es de Caracas, Venezuela y está estudiando lingüística en la Universidad de

Friburgo. Desde 2017 trabaja para la revista online Josha Journal, que incluye actividades periodísticas. Maria Sandoval es también violonchelista y estudió música en el Conservatorio de Música Simón Bolívar de Caracas, y actualmente trabaja con el proyecto social "Orchestra con anima Freiburg" para animar a los jóvenes fugitivos a hacer música juntos. 